\title{
BMJ Open Estimating the burden of hypertension and its significant risk factors among male commercial drivers in sub-Saharan Africa: A systematic review and meta- analysis
}

\author{
Martin Ackah (D) ,1,2 Louise Ameyaw, ${ }^{2}$ Mohammed Gazali Salifu (D) ,2,3 \\ Cynthia Osei Yeboah ${ }^{1}$
}

To cite: Ackah M, Ameyaw L, Salifu MG, et al. Estimating the burden of hypertension and its significant risk factors among male commercial drivers in sub-Saharan Africa: A systematic review and meta-analysis. BMJ Open 2021;11:e053825. doi:10.1136/ bmjopen-2021-053825

- Prepublication history and additional supplemental material for this paper are available online. To view these files, please visit the journal online (http://dx.doi.org/10.1136/ bmjopen-2021-053825).

Received 25 May 2021 Accepted 29 November 2021

Check for updates

(c) Author(s) (or their employer(s)) 2021. Re-use permitted under CC BY-NC. No commercial re-use. See rights and permissions. Published by BMJ.

${ }^{1}$ Department of Physiotherapy, Korle Bu Teaching Hospital,

Accra, Ghana

${ }^{2}$ Department of Epidemiology and Disease Control, University of Ghana, Legon, Ghana

${ }^{3}$ Department of Policy Planning Budgeting Monitoring and Evaluation Directorate, Ministry of Health, Accra, Ghana

Correspondence to

Martin Ackah;

martinackah10@gmail.com

\section{ABSTRACT}

Objective The study was designed to assess the burden and significant risk factors among male commercial drivers in sub-Saharan Africa (SSA).

Design Systematic review and meta-analysis.

Data sources Medline via PubMed, Google Scholar, Cochrane databases and Africa Journal Online were searched from January 2010 to December 2020.

Eligibility criteria for selecting studies The authors included observational studies reporting on the burden and/or risk factors for hypertension among commercial drivers in SSA. Male adult population $\geq 18$ years working as a commercial driver in SSA as well articles published in English.

Data extraction and synthesis Two independent coauthors used a prepared data extraction form to extract data from the eligible published papers and assessed the risk of bias. DerSimonian and Laird random effects model was used to pool the burden of hypertension and significant risk factors among male commercial drivers in SSA. The presence of heterogeneity among studies was quantified by estimating variance using both Cochrane's $Q$ statistics and the $\mathrm{I}^{2}$ statistics. A subgroup and sensitivity analyses were performed.

Results Overall, 14 articles met the inclusion criteria involving a total of 4285 male commercial drivers in SSA. The estimated pooled burden of hypertension among the male commercial drivers in SSA was $32 \%$ (95\% Cl $24 \%$ to $39 \%)$. The risk factors identified were age $\mathrm{OR}=1.10$ (95\% $\mathrm{Cl} 1.06$ to 1.15$)$, overweight/obese $\mathrm{OR}=3.38(95 \%$ $\mathrm{Cl} 2.46$ to 4.29$)$, alcohol consumption $\mathrm{OR}=3.00(95 \% \mathrm{Cl}$ 2.05 to 3.95 ) and duration of driving ( $\geq 5$ years) $0 \mathrm{R}=1.83$ (95\% Cl 1.03 to 2.63). Funnel plot inspection and Egger's regression test of small effect (0.5838) showed no evidence of publication bias.

Conclusions Our review showed that nearly one-third of male commercial drivers in SSA have hypertension. Reduction of modifiable risk factors such as overweight/ obesity, alcohol consumption and long-term driving through multifaceted implementation strategies are recommended for prevention and control of hypertension among male commercial drivers in SSA.

Trial registration number CRD42021250910.
Strengths and limitations of this study

- This is the first systematic review and meta-analysis on the burden of hypertension and significant risk factors among male commercial drivers in subSaharan Africa (SSA).

- Our results are more reliable evident by no obvious publication bias, and based on the cut-off point of $70 \%$, majority of the studies (93\%) yielded low risk of bias

- Despite the fact that non-English papers and publications published before 2010 were eliminated, the funnel and Egger's test revealed no evidence of publication bias.

- This review was conducted among commercial male drivers in SSA; hence, the results cannot be generalised to the general population in SSA.

- The significant heterogeneity among the studies is the key limitation.

\section{INTRODUCTION}

The assessment of disease burdens is an important component of health policy growth. ${ }^{1}$ Hypertension is a public health concern, particularly in sub-Saharan Africa (SSA), where there is evidence of significant underdiagnosis, care and control. ${ }^{2}$

Hypertension is a chronic medical condition, defined as having an elevated blood pressure of $\geq 140 / 90 \mathrm{~mm} \mathrm{Hg}$ according to the Joint National Committee (JNC). ${ }^{3}$ Hypertension is the most common cardiovascular condition globally, with a prevalence of about one billion people worldwide. It continues to be the leading single contributor to global disease and mortality, accounting for about 9.4 million deaths each year through its various complications. ${ }^{45}$

Hypertension, which was uncommon in SSA, has now become an emerging health threat 
due to increased risk factors from lifestyle changes. ${ }^{6}$ Some common risk factors include smoking, excessive alcohol consumption, sedentary lifestyle, obesity and unhealthy diet (eg, high salt intake and reduced consumption of fruit and vegetable). ${ }^{78} \mathrm{SSA}$ is however currently fighting infectious diseases like malaria and HIV, with most of the region's governments already having scanty resources and health budgets. As a result, an increase in the prevalence of hypertension in this area is likely to have serious consequences, as few people will be treated and control will be poor. ${ }^{2}$

People with hypertension do not manifest any symptoms early in the disease process but may progress to develop complications like stroke, heart disease and renal disease over time ${ }^{68}$ Early recognition and treatment are essential in controlling the progress of the disease especially in countries with limited resources and budgets like SSA and low-income and middle-income countries (LMICs).

Commercial drivers play a very significant role in motorised transport for people as well as goods and services. Nonetheless, there is a high prevalence of unrecognised hypertension among these drivers. ${ }^{9}{ }^{10}$ Due to the nature of the work of these commercial drivers, there is an increased risk of developing hypertension among them. Drivers in LMICs have to endure the constant stress of traffic congestion, poor traffic regulation and poor road conditions. ${ }^{1011}$ As a results, some resort to alcohol consumption and smoking as a means of relieving stress ${ }^{10}$ both of which are modifiable risk factors predisposing them to development of hypertension. Long hours of driving with minimal physical activity encourages a sedentary lifestyle, further increasing this risk. ${ }^{12}$ There is an increased susceptibility to poor lifestyle habits like unhealthy diet ${ }^{13}$ and irregular sleep patterns. ${ }^{11}$

Ensuring good health is maintained among commercial drivers will play an important role in promoting safety among these drivers as well as the general public who patronise their services. Globally, a previous systematic review and meta-analysis has estimated the burden of hypertension among professional drivers to be $34 \%$ (95\% CI $27 \%$ to $40 \%) .{ }^{11}$ However, such review included only studies from Nigeria to represent the whole of SSA and by extension Africa. Furthermore, previous review only estimated the burden without taking into account the possible risk factors responsible for such occurrences.

In light of this, we conducted a systematic review and meta-analysis with the aim of estimating disease burden of hypertension and significant risk factors among male commercial drivers in SSA. This could help put in place public health measures to reduce the risk factors identified in order to prevent hypertension or ensure early diagnosis and treatment to reduce adverse health event.

\section{Review questions}

- What is the pooled prevalence for hypertension among male commercial drivers in SSA?

- What are the significant risk factors for hypertension among male commercial drivers in SSA?

\section{METHODS}

\section{Patient and public involvement}

There was no direct patient or public involvement in this study.

\section{Systematic review and protocol registration}

This systematic review and meta-analysis was conducted and reported according to the guidelines of the Preferred Reporting Items for Systematic Reviews and Meta-Analyses $^{14}$ (checklist file). The current review is registered with International Prospective Register of Systematic Reviews database (registration number: CRD42021250910).

\section{Eligibility criteria}

Type of studies

Primary studies for inclusion were: cross sectional, case control, cohort, conference abstracts, theses and longitudinal studies from SSA. Original observational studies published in English. The present review excluded studies: reviews, commentaries, letter to editors and animal studies.

\section{Participants}

Male adult population $\geq 18$ years working as a commercial driver in SSA. Studies on hypertension in commercial drivers from SSA nations. The review excluded: hypertension studies on non-commercial drivers in SSA, hypertension studies among children (under 18 years).

\section{Outcome}

The primary outcome was to determine the burden of hypertension among male commercial drivers in SSA. The secondary outcome was to assess the significant risk factors of hypertension among male commercial drivers in SSA. In this study, the authors considered both recognised and unrecognised hypertension. Hypertension was defined according to JNC criteria, systolic blood pressure of $\geq 140 \mathrm{~mm} \mathrm{Hg}$ and/or, diastolic blood pressure of $\geq 90 \mathrm{~mm} \mathrm{Hg} .{ }^{15}$

\section{Data sources and search strategies}

Primary electronic search in English on the burden of hypertension among male commercial drivers in SSA through Medline via PubMed, Google Scholar, Africa Journal Online (AJOL), and Cochrane Library for relevant studies. It is established fact that between 2000 and 2010, the burden of hypertension in high-income nations fell by $2.6 \%$, while awareness, treatment and control all improved significantly. LMICs reported a $7.7 \%$ increase in prevalence over the same 10-year period, with little improvement in awareness, treatment and control. ${ }^{16}$ Hence, to understand what is currently happening in the last decade among commercial drivers in SSA, the search was restricted to studies published between January 2010 to December 2020. The abstracts of all eligible papers were reviewed and full articles were similarly accessed through PubMed, Google Scholar and AJOL. To find additional studies not included in our electronic search, 
reference lists of papers that met the eligibility criteria were also reviewed. A snowball scan of similar papers' references for related articles was also carried out. In addition, grey literature such as dissertation databases were accessed through online university repositories and experts were contacted to ensure that potentially relevant studies that were undetected by the search of electronic databases were captured. On 10 May 2021, the final search was completed.

Articles were searched by examining the full title ("Burden of Hypertension and common risk factors among Male Commercial Drivers in Sub-Saharan Africa") and then keywords ("Hypertension" "High blood pressure" "unrecognised hypertension" "diastolic hypertension" "systolic hypertension" "Cardiometabolic" "risk factors" "commercial drivers" "Sub-Saharan Africa"). The Boolean operators "OR" and "AND" were used to combine these keywords. The full search strategies for the various electronic databases can be found in online supplemental file 1 .

\section{Screening and selecting studies}

Two independent authors performed an initial screening of studies based on the details found in their titles and abstracts. The same independent investigators performed the full-paper screening. Disagreements were resolved by consensus. To ensure that independent reviewers apply the selection criteria consistently, a screening guide was used. $^{17}$

\section{Data extraction and management}

Two independent coauthors (MA and LA) extracted data from the eligible published articles using a prepared data extraction form. Data such as the last name of the first author, year of publication, type of study, country, sample size, number of cases with hypertension and significant risk factors information were extracted. Consensus meetings were held to resolve any discrepancies. Article titles and abstracts retrieved from the search were managed and stored in Mendeley reference manager in order for duplicated articles to be removed.

\section{Quality assessment}

The 9-item Joanna Briggs Institute Critical Appraisal Checklist for prevalence studies was used to assess the quality of the retrieved studies. ${ }^{18} 19$ The purpose of this assessment was to determine the internal and external validity of the studies and to minimise risk of bias. ${ }^{19} \mathrm{~A}$ $70 \%$ cut-off was used to classify studies as having a low or high risk of bias $^{20}$ (ie, $<70=$ high risk and $\geq 70=$ low risk).

\section{Data synthesis and strategy}

A meta-analysis employing the random effect model (ie, DerSimonian and Laird random-effect model) was done due to the presence of heterogeneity $\left(\mathrm{I}^{2}=83.23 \%\right)$ to estimate the pooled burden of hypertension among male commercial drivers in SSA. This was visually represented using the forest plot. The presence of heterogeneity among studies was quantified by estimating variance using both Cochrane's $Q$ statistics and the $\mathrm{I}^{2}$ statistics. ${ }^{21}$ The $\mathrm{I}^{2}$ takes values between $0 \%$ and $100 \%$, and a value of $0 \%$ indicates absence of heterogeneity. $\mathrm{I}^{2}$ was interpreted based on Higgins and Thompson classification, percentages of $25 \%, 50 \%$ and $75 \%$ was considered as low, moderate and high heterogeneity, respectively ${ }^{21}$

A subgroup analysis was performed to determine the sources of heterogeneity on the study characteristics (year of publication ( $\leq 2016$ and $>2016$ ), and sampling strategy). A sensitivity analysis was performed to determine the robustness of the estimates obtained from the meta-analysis (ie, the impacts of a single study on the total pooled estimate were investigated using a leave one out sensitivity analysis). OR and associated $95 \%$ CI were extracted to assessed the risk factors of hypertension among the study population in SSA. A risk factor was eligible for meta-analysis if it had been assessed and data from at least two studies were available. The funnel plot and Egger's regression test were used to screen for publication bias.

All statistical analyses were performed using Stata (Stata Statistical Software: Release 16; College Station, TX; Stata Corp LP) software and Microsoft Office 2013. The significance level was set at $5 \%$.

\section{RESULTS}

\section{Study selection process}

The authors identified 4506 from the search. After removing 2046 duplicate papers, 2460 were left for abstract and title screening. Four hundred (400) articles were excluded for irrelevant papers. Following fulltext review of the 100 eligible articles, 80 were excluded because outcomes of interest were not reported in 36 articles and 50 non-SSA papers. Finally, 14 articles met the inclusion criteria involving a total of 4285 male commercial drivers in SSA (figure 1).

\section{Characteristics of the included studies and quality assessment}

The characteristics of the included studies are shown in table 1. The studies were published between 2013 and 2020. Probability sampling strategy were predominant $(57 \%)$. Ascendingly, the studies were mostly from Nigeria, Ghana, South Africa and Ethiopia. The sample size ranged from 100 to 614 with estimated total sample of 4285 . Based on the cut-off point of $70 \%$, majority of the studies (93\%) had low risk of bias (online supplemental file 2).

\section{Burden of hypertension among male commercial drivers in SSA}

From figure 2, the burden of hypertension among male commercial drivers in SSA ranged from $9 \%$ to $63 \%$. Metaanalysis showed an estimated pooled prevalence of $32 \%$ (95\% CI 24\% to 39\%) based on DerSimonian and Laird 

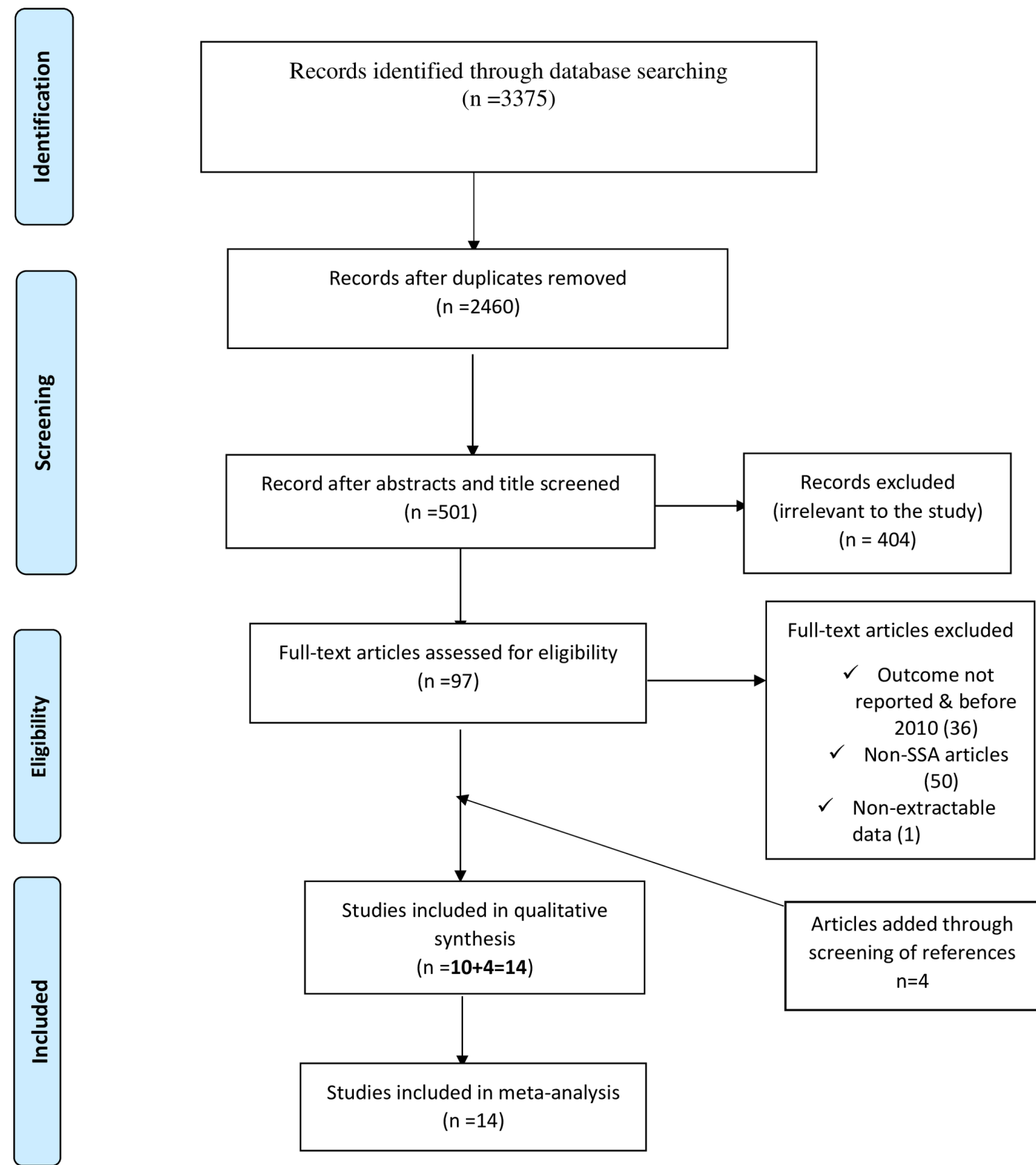

Figure 1 Preferred Reporting Items for Systematic Reviews and Meta-Analyses-adapted flow showing the results of the search.

random-effect model. A substantial statistically significant heterogeneity was detected across the studies $\left(\mathrm{I}^{2}=83.23 \%\right.$, $\mathrm{p}=0.00)$.

\section{Subgroup and sensitivity analyses}

As shown in figure 3, the subgroup analysis was based on the sampling strategy and categorised year of publication to assess the sources of heterogeneity. The pooled prevalence studies that used non-probability sampling was 39\% (95\% CI $25 \%$ to $52 \%$ ) and probability sampling method was $27 \%$ (95\% CI $19 \%$ to $34 \%$ ). For year of publication, studies that were published before 2017 and after 2017 had an estimated burden of $24 \%$ (95\% CI $15 \%$ to $34 \%$ ) and $37 \%$ (95\% CI $27 \%$ to $47 \%$ ), respectively.
We performed sensitivity tests by removing one study at a time and recalculating the pooled effect estimate of the remaining studies on the pooled burden of hypertesnion. The findings showed that there is no influential study on the pooled outcome. The pooled estimated burden of hypertension ranged from $29.0 \%$ (95\% CI $23.0 \%$ to $36.0 \%$ ) to $34 \%$ (95\% CI $26.0 \%$ to $41.0 \%$ ) (online supplemental file 3$)$.

\section{Publication bias}

Symmetrical inspection using the funnel plot (figure 4) and Egger's regression test of small effect (0.5838) showed no evidence of publication bias. 


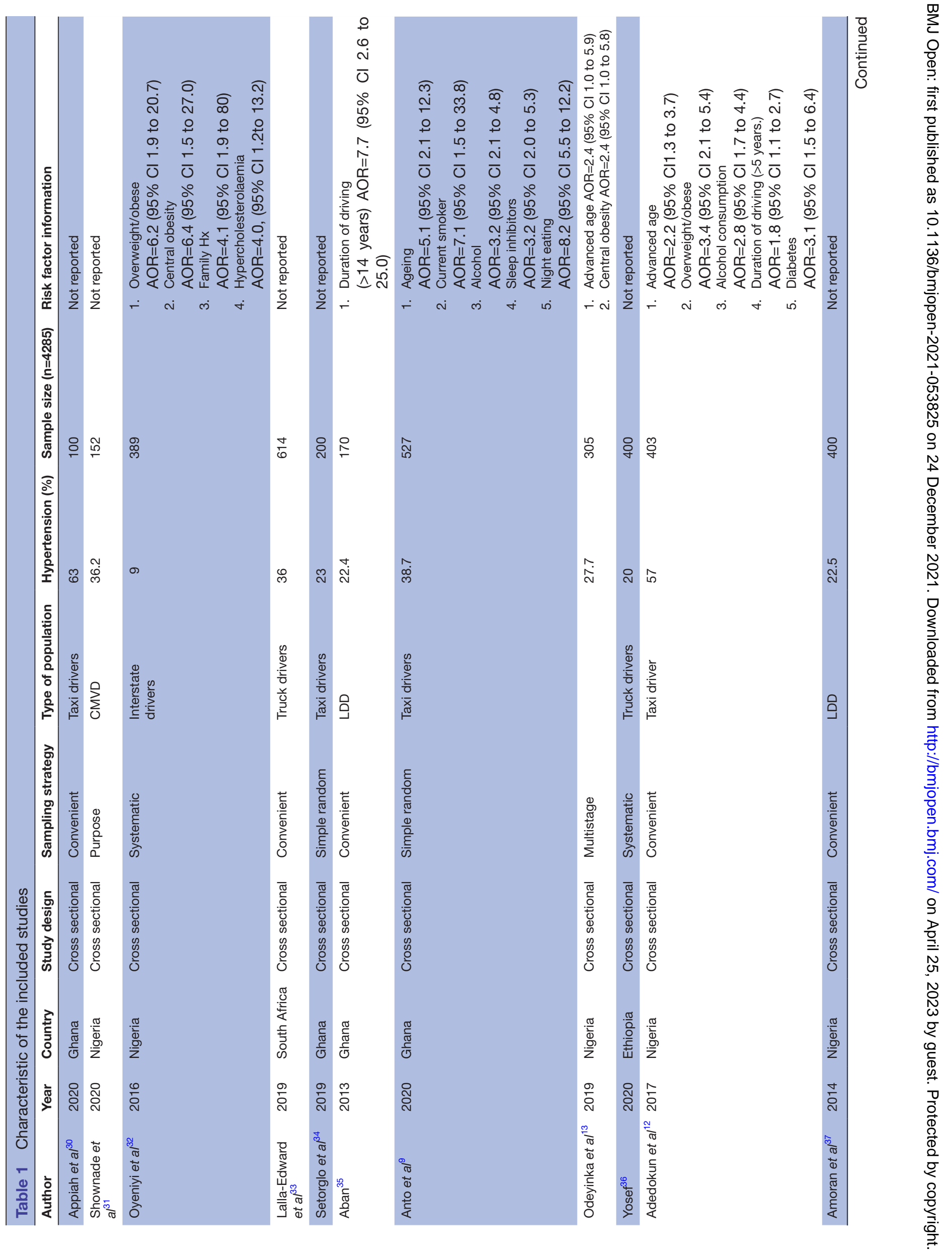


Risk factors associated with hypertension among male commercial drivers in SSA

Out of the 14 included articles, 7 were synthesised for the risk factors analysis (online supplemental file 4). The remaining seven studies either did not report or adjust the variables in their analysis. The results of the pooled risk factor analysis are demonstrated in table 2. There was an increased odds of hypertension with advanced age, overweight/obese, alcohol consumption, duration of driving ( $\geq 5$ years) and central obesity. For instance, an advanced age increased the odds of hypertension by $10 \%$, overweight/obese male drivers had 3.38 times odds of developing hypertension, excessive alcohol consumption increased the odds of hypertension by three times, longer duration of driving ( $\geq 5$ years) increased odds of hypertension by $83 \%$, and male commercial drivers with central obesity had 2.25 times odds of developing hypertension in SSA (table 2).

\section{DISCUSSION \\ Burden of hypertension among male commercial drivers in SSA}

This is the first systematic review and meta-analysis to estimate the burden and common risk factors among male commercial drivers in SSA to the best of our knowledge. The overall estimated burden of hypertension among male commercial drivers was $32 \%$ (95\% CI $24 \%$ to $39 \%$ ). This is comparable to the global estimate $31.1 \%(95 \%$ CI 30.0 to 32.0) and in low and middle income estimate of $31.5 \%$ (95\% CI $30.1 \%$ to $32.9 \%$ ) published in 2010 among the general population. ${ }^{22}$ However, the current estimate is lower than global estimate of professional drivers $34 \%$ (95\% CI $27 \%$ to $40 \%$ ). ${ }^{11}$ This is unsurprising as the global estimate included more studies from LMICs. Indeed, data show that burden of hypertension in LMICs increased by $7.7 \%$ from 2000 to $2010 .^{22}$

Stratification by year of publication demonstrate that article published from 2013 to 2016 had a decrease estimate by 8 percentage points. However, articles published from 2017 and above had an increase estimate by 5 percentage points from the overall estimated burden. This clearly demonstrates that hypertension is on the rise among commercial drivers in SSA and hence urgent public health action to address the problem is paramount.

\section{The significant risk factors for hypertension among male commercial drivers in SSA}

Overall, five risk factors were identified and further categorised into modifiable and non-modifiable risk factors. The modifiable factors were overweight/obese, alcohol consumption, duration of driving ( $\geq 5$ years) and central obesity. The non-modifiable risk factor was advanced age. Five studies reported on overweight/obese and advanced age each while two studies reported each on alcohol consumption, duration of driving ( $\geq 5$ years) and central obesity as a risk factor for hypertension. 


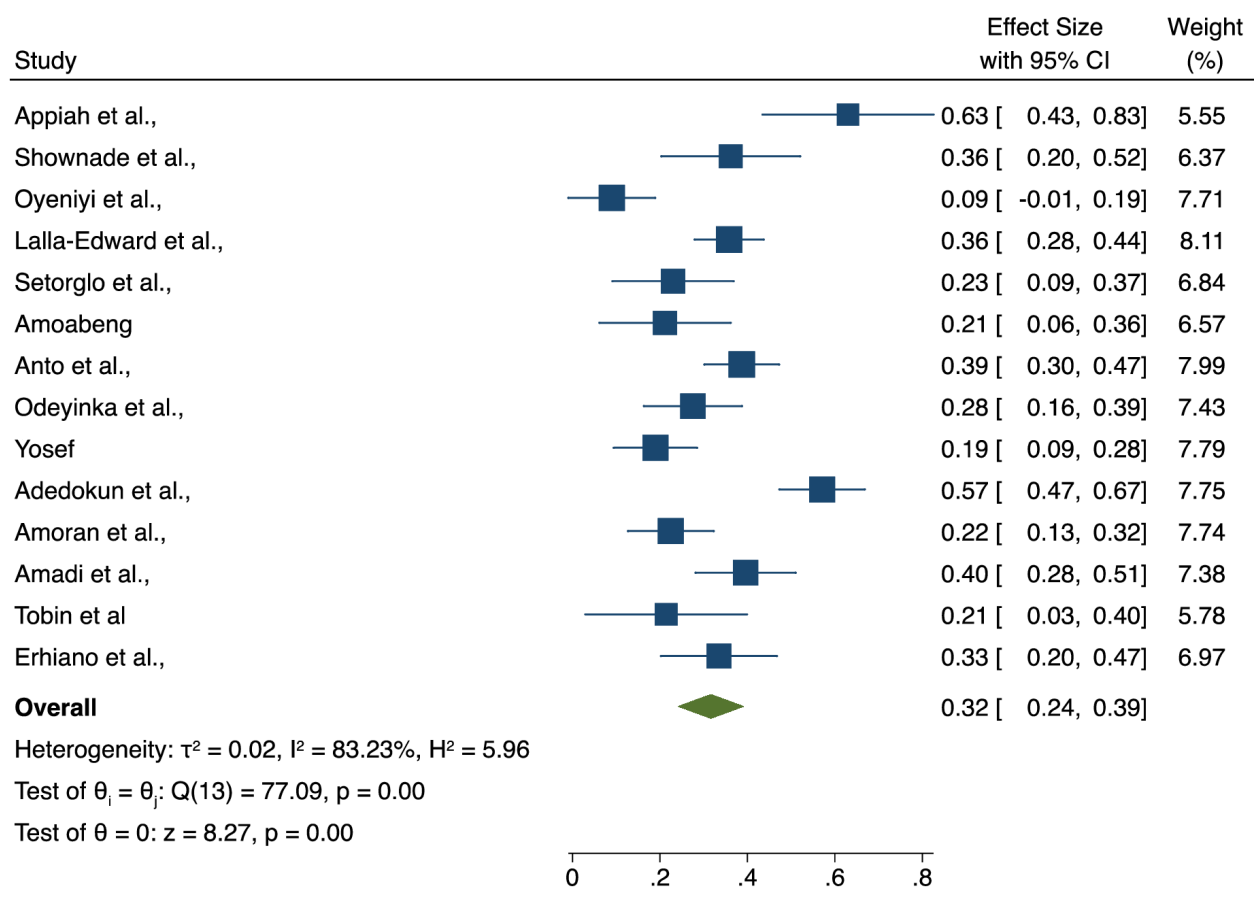

Random-effects REML model

Figure 2 Forest plot of pooled Burden of hypertension among male commercial drivers in sub-Saharan Africa (SSA). REML; Residual Maximum Likelihood.

The present review revealed an association between advanced age and hypertension among the male commercial drivers in SSA. This finding is consistent with recent systematic review and meta-analysis in Ethiopia ${ }^{23}$ and observational studies in Ghana ${ }^{24}$ and four SSA countries. ${ }^{4}$ The possible explanation could be due to the biological impact of increased arterial resistance as a result of arterial thickening and stiffness as people age. ${ }^{25}$

Another important risk factor identified in the current review were overweight/obesity and abdominal obesity. Overweight/obesity was noted to increase hypertension by 3.38 -fold in commercial male drivers in SSA as compared with normal weight. Though, abdominal obesity was found to increase hypertension by 2.25 -fold among male commercial drivers, it was not statistically significant. Obesity is considered to be a risk factor for a variety of diseases, including hypertension, diabetes and vascular disease, and has become epidemic in many parts of the world.$^{26}$ Lifestyle modifications in conjunction with other public health intervention continuously throughout the commercial drivers' lifespan will be of utmost important to curb this menace.

The pooled analysis showed that alcohol consumption was associated with hypertension in male commercial drivers in SSA. Alcohol consumption was associated with threefolds increase risk of hypertension. This outcome

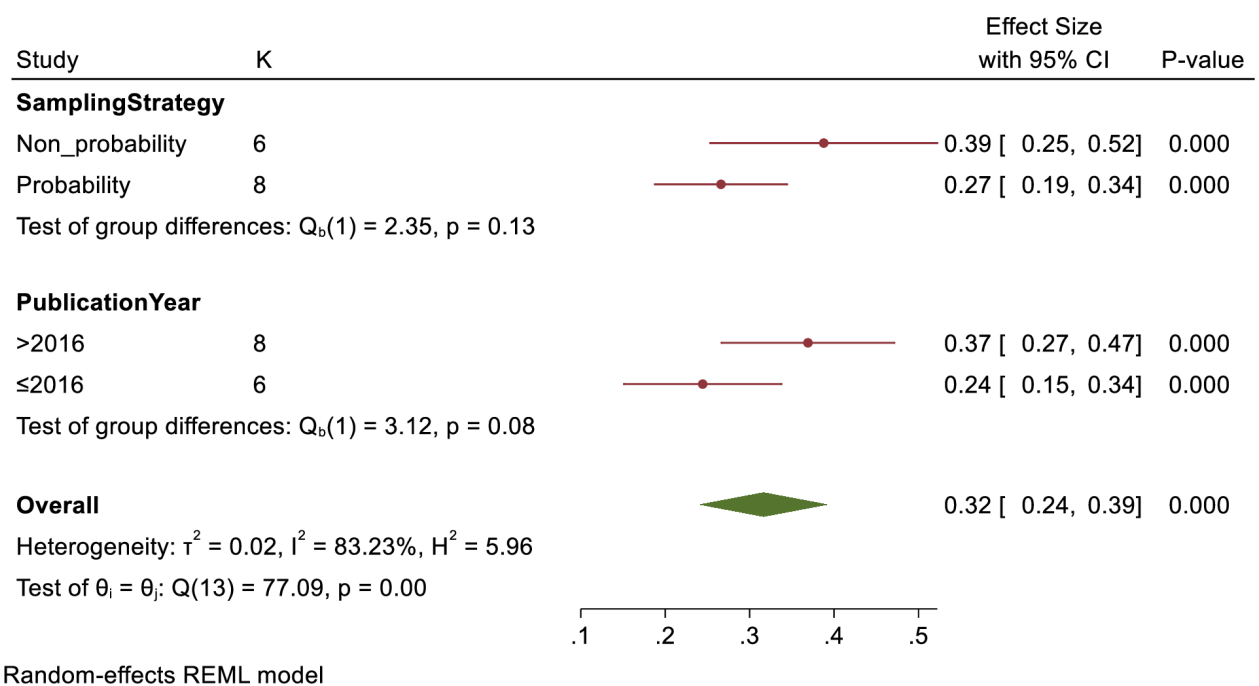

Figure 3 Forest plot of burdden of hypertension among male comercial drivers in sub-Saharan Africa stratifed by sampling strategy and year of publication. REML; Residual Maximum Likelihood. 


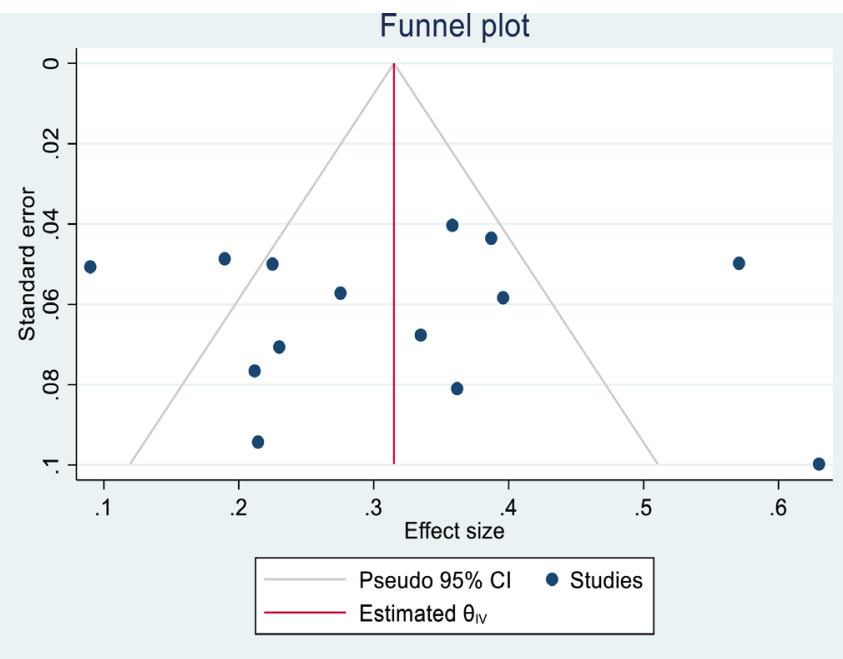

Figure 4 Assessment of publication bias.

is confirmed by several systematic review and metaanalyses that any alcohol consumption is associated with an increased risk for hypertension in men. ${ }^{27}{ }^{28}$ It is no wonder that WHO Global Action Plan for the Prevention of Non-Communicable Diseases (NCDs) calls for a $10 \%$ reduction in unhealthy alcohol usage and a $25 \%$ reduction in high blood pressure by 2025 in order to reduce NCD mortality by $25 \% .{ }^{29}$ Therefore, prioritisation and implementation of successful alcohol therapies for male commercial drivers that can significantly reduce the disease burden caused by hypertension should be encouraged.

Furthermore, period of driving was another identified risk for hypertension among male commercial drivers in SSA. The commercial driver who had driven for at least 5 years had $83 \%$ increased risk of hypertension. This could be attributed to the fact that drivers behind the steer have minimal physical activity that encourages a sedentary lifestyle and puts them at risk of developing hypertension. ${ }^{12}$

Lastly, smoking was not identified as a risk factor in the current review because only one study from Ghana ${ }^{9}$ reported on it hence could not be meta-analysed. It could also mean that, this essential factor (ie, smoking) is not prevalence among commercial drivers in SSA, and as a result many studies in the subregion did not report on it.

Table 2 Pooled risk factors of hypertension among male commercial drivers in sub-Saharan Africa

\begin{tabular}{|c|c|c|c|c|}
\hline No & Risk factor & OR & $95 \% \mathrm{Cl}$ & $I^{2}$ \\
\hline \multicolumn{5}{|c|}{ Non-modifiable risk factors } \\
\hline 1. & Advanced age & 1.10 & 1.06 to 1.15 & $76.3 \%$ \\
\hline \multicolumn{5}{|c|}{ Modifiable risk factors } \\
\hline 1. & Overweight/Obese & 3.38 & 2.46 to 4.29 & $0.0 \%$ \\
\hline 2. & Alcohol consumption & 3.00 & 2.05 to 3.95 & $0.0 \%$ \\
\hline 3. & Period of driving ( $\geq 5$ years) & 1.83 & 1.03 to 2.63 & $5.7 \%$ \\
\hline 4. & Central obesity & 2.25 & 0.18 to 4.90 & $0.0 \%$ \\
\hline
\end{tabular}

The main limitations are the heterogeneity that existed among studies. Nonetheless, this is the first systematic review and meta-analysis on the burden of hypertension and common risk factors among male commercial drivers in SSA. Our results are more reliable evident by no obvious publication bias and based on the cut-off point of $70 \%$, majority of the studies $(93 \%)$ yielded low risk of bias.

\section{CONCLUSION}

This is the first systematic review and meta-analysis on the burden of hypertension and common risk factors among male commercial drivers in SSA to the best of our knowledge. Hypertension is a significant public health problem among male commercial drivers. For example, our review showed that nearly one in three male commercial drivers in SSA have hypertension. Reduction of modifiable risk factors such as overweight/obesity, alcohol consumption and long-term driving through multifaceted implementation strategies are recommended for prevention and control of hypertension among male commercial drivers in SSA.

Acknowledgements The authors would like to express their gratitude to all who contributed to the writing of the reviewed primary articles in this systematic review and meta-analysis.

Contributors MA conceptualised the study, search strategy, data extraction, literature search, writing of the manuscript, data analysis, and critically revised the manuscript for methodological and intellectual content. LA was involved in the search strategy, data extraction, and literature search and critically revised the manuscript for methodological and intellectual content. MGS was involved in the writing of the manuscript and planned the study. COY was involved in the drafting the manuscript. All authors approved the final manuscript. MA is the guarantor of the review.

Funding The authors have not declared a specific grant for this research from any funding agency in the public, commercial or not-for-profit sectors.

Competing interests None declared.

Patient consent for publication Not applicable.

Ethics approval This study does not involve human participants. The systematic review and meta-analysis use primary data synthesis; hence, ethics approval is not required.

Provenance and peer review Not commissioned; externally peer reviewed.

Data availability statement All data relevant to the study are included in the article or uploaded as supplementary information.

Supplemental material This content has been supplied by the author(s). It has not been vetted by BMJ Publishing Group Limited (BMJ) and may not have been peer-reviewed. Any opinions or recommendations discussed are solely those of the author(s) and are not endorsed by BMJ. BMJ disclaims all liability and responsibility arising from any reliance placed on the content. Where the content includes any translated material, BMJ does not warrant the accuracy and reliability of the translations (including but not limited to local regulations, clinical guidelines, terminology, drug names and drug dosages), and is not responsible for any error and/or omissions arising from translation and adaptation or otherwise.

Open access This is an open access article distributed in accordance with the Creative Commons Attribution Non Commercial (CC BY-NC 4.0) license, which permits others to distribute, remix, adapt, build upon this work non-commercially, and license their derivative works on different terms, provided the original work is properly cited, appropriate credit is given, any changes made indicated, and the use is non-commercial. See: http://creativecommons.org/licenses/by-nc/4.0/.

ORCID iDs

Martin Ackah http://orcid.org/0000-0002-5045-1104 
Mohammed Gazali Salifu http://orcid.org/0000-0003-2025-5337

\section{REFERENCES}

1 Lim SS, Vos T, Flaxman AD, et al. A comparative risk assessment of burden of disease and injury attributable to 67 risk factors and risk factor clusters in 21 regions, 1990-2010: a systematic analysis for the global burden of disease study 2010. Lancet 2012;380:2224-60.

2 Addo J, Smeeth L, Leon DA. Hypertension in sub-Saharan Africa: a systematic review. Hypertension 2007;50:1012-8.

3 Chobanian AV, Bakris GL, Black HR, et al. Seventh report of the joint National Committee on prevention, detection, evaluation, and treatment of high blood pressure. Hypertension 2003;42:1206-52.

4 Guwatudde D, Nankya-Mutyoba J, Kalyesubula R, et al. The burden of hypertension in sub-Saharan Africa: a four-country cross sectional study. BMC Public Health 2015;15:1-8.

5 Poulter NR, Prabhakaran D, Caulfield M. Hypertension. Lancet 2015;386:801-12.

6 BeLue R, Okoror TA, Iwelunmor J, et al. An overview of cardiovascular risk factor burden in sub-Saharan African countries: a socio-cultural perspective. Global Health 2009;5:10.

7 van de Vijver S, Akinyi H, Oti S. Status report on hypertension in Africa - Consultative review for the 6th Session of the African Union Conference of Ministers of Health on NCD's. Pan Afr Med J 2013;16:1937-8688.

8 Princewel F, Cumber SN, Kimbi JA, et al. Prevalence and risk factors associated with hypertension among adults in a rural setting: the case of Ombe, Cameroon. Pan Afr Med J 2019;34:147.

9 Anto EO, Owiredu WKBA, Adua E, et al. Prevalence and lifestylerelated risk factors of obesity and unrecognized hypertension among bus drivers in Ghana. Heliyon 2020;6:e03147.

10 Lakshman A, Manikath N, Rahim A, et al. Prevalence and risk factors of hypertension among male occupational bus drivers in North Kerala, South India: a cross-sectional study. ISRN Prev Med 2014;2014:1-9.

11 Krishnamoorthy Y, Sarveswaran G, Sakthivel M. Prevalence of hypertension among professional drivers: evidence from 2000 to 2017-A systematic review and meta-analysis. J Postgrad Med 2020;66:81-9.

12 Adedokun AO, Ter Goon D, Owolabi EO, et al. Driving to better health: screening for hypertension and associated factors among commercial TAXI drivers in buffalo City metropolitan Municipality, South Africa. Open Public Health J 2017;10:303-12.

13 Odeyinka O, Ajayi I. Prevalence of hypertension and diabetes and their determinants among commercial drivers in Ibadan Metropolis, south-western Nigeria. Niger J Cardiol 2017;14:75.

14 Page MJ, McKenzie JE, Bossuyt PM. The PRISMA 2020 statement: an updated guideline for reporting systematic reviews. BMJ 2021;372.

15 James PA, Oparil S, Carter BL, et al. 2014 evidence-based guideline for the management of high blood pressure in adults: report from the panel members appointed to the eighth joint National Committee (JNC 8). JAMA 2014;311:507-20.

16 Das C, Hansen KC, Tyler JK LMS. Global disparities of hypertension prevalence and control: a systematic analysis of population-based studies from 90 countries. Physiol Behav 2017;176:139-48.

17 Ackah M, Yeboah CO, Ameyaw L. Risk factors for 30-day inhospital mortality for in-patient with stroke in sub-Saharan Africa: protocol for a systematic review and meta-analysis. BMJ Open 2021;11:e049927-12.

18 Munn Z, Moola S, Lisy K, et al. Methodological guidance for systematic reviews of observational epidemiological studies reporting prevalence and cumulative incidence data. Int J Evid Based Healthc 2015;13:147-53.
19 JBI. The Joanna Briggs Institute: the systematic review of economic evaluation evidence, 2014. Available: www.joannabriggs.org

20 Torgbenu E, Luckett T, Buhagiar MA, et al. Prevalence and incidence of cancer related lymphedema in low and middle-income countries: a systematic review and meta-analysis. BMC Cancer 2020;20:1-20.

21 Higgins JPT, Thompson SG. Quantifying heterogeneity in a metaanalysis. Stat Med 2002;21:1539-58.

22 Mills KT, Bundy JD, Kelly TN, et al. Global disparities of hypertension prevalence and control. Circulation 2016;134:441-50.

23 Legese N, Tadiwos Y, Nanati LYT. Epidemiology of hypertension in Ethiopia: a systematic review. Integr Blood Press Control 2020;13:135-43.

24 Agyemang C. Rural and urban differences in blood pressure and hypertension in Ghana, West Africa. Public Health 2006;120:525-33.

25 Abebe SM, Berhane Y, Worku A, et al. Prevalence and associated factors of hypertension: a crossectional community based study in Northwest Ethiopia. PLoS One 2015;10:e0125210-1.

26 Kay GG, Mclaughlin D. Relationship between obesity and driving 2014.

27 Roerecke M, Tobe SW, Kaczorowski J, et al. Sex-Specific associations between alcohol consumption and incidence of hypertension: a systematic review and meta-analysis of cohort studies. J Am Heart Assoc 2018;7. doi:10.1161/JAHA.117.008202. [Epub ahead of print: 2706 2018].

28 Liu F, Liu Y, Sun X. Nutrition, metabolism \& cardiovascular diseases race- and sex-specific association between alcohol consumption and hypertension in 22 cohort studies: a systematic review and. Nutr Metab Cardiovasc Dis 2020.

29 WHO. Global status report on noncommunicable diseases, 2014.

30 Appiah CA, Afriyie EO. Frank Ekow Atta Hayford EF. prevalence and clusters of modifiable cardiovascular disease risk factors among intra-city commercial motor vehicle drivers in a Nigerian metropolitan City. Ghana Med J 2020;54:100-9.

31 Showande SJ, Odukoya IO. Prevalence and clusters of modifiable cardiovascular disease risk factors among intra-city commercial motor vehicle drivers in a Nigerian metropolitan City. Ghana Med J 2020;54:100-9.

32 Olusegun SO, Ikeoluwapo OA. Prevalence of hypertension and associated risk factor among Interstate commercial drivers in Jabi Park Abuja. Int. J. Med. Med. Sci. 2016;8:75-83.

33 Lalla-Edward ST, Fischer AE, Venter WDF, Francois Venter WD, et al. Cross-Sectional study of the health of southern African truck drivers. BMJ Open 2019;9:e032025:1-11.

34 Setorglo J, Gorleku PN, Appeatu D. Hypertension prevalence and predictors among TAXI drivers at Abura in Cape coast Metropolis of Ghana. J Public Heal Policy Plann 2019;3.

35 Abban H. Cardiovascular diseases risk factors among commercial, 2013: 10363220.

36 Yosef T. Prevalence and associated factors of chronic noncommunicable diseases among cross-country truck drivers in Ethiopia. BMC Public Health 2020;20:1-7.

37 Amoran OE. Albert Adekunle Salako OJ. screening for common occupational health diseases among long distance professional drivers in Sagamu, Ogun state, Nigeria ثيبر علا ثغلن. Int J Prev Med 2014;5:516-21.

38 Amadi CE, Grove TP, Mbakwem AC, et al. Prevalence of cardiometabolic risk factors among professional male long-distance bus drivers in Lagos, south-west Nigeria: a cross-sectional study. Cardiovasc J Afr 2018;29:106-14.

39 Tobin EA, Ofili AN, Asogun DA. Original article prevalence of hypertension and associated factors among Inter-City drivers in an urban City in South-South. Int J repiractory Med 2013;2:5-12.

40 Erhiano E, Igbokwe V, El-Khashab M. Prevalence of hypertension among commercial bus drivers in Sokoto, Sokoto state Nigeria. Int Invent J Med Med Sci 2015;2:34-9. 